\title{
LOS TROFEOS DE POMPEYO «IN PYRENAEI IUGIS»
}

\author{
POR \\ JAVIER ARCE \\ Escuela Española de Historia y Arqueología del C.S.I.C.. Roma
}

\section{RESUMEN}

Se examina en este articulo la reciente propuesta, realizada por un equipo de arqueólogos españoles y franceses. del descubrimiento y posterior reconstrucción de los trofeos de Pompeyo en Panissars (Pirineos Orientales). Consecuentemente se analiza toda la documentación literaria existente a este propósito y se estudian los monumentos triunfales contemporáneos. A la vista del análisis parece inaceptable la reconstrucción que se ha hecho hasta el momento de dicho monumento y se proponen alternativas que se consideran mas acordes con monumentos contemporáneos similares.

\section{SUMMARY}

This article examines the recent proposal put forward by a group of Spanish and French archeologists of the discovery and reconstruction of the trophies of Pompey at Panissars in the Eastern Pyrenees. After a revision of the literary evidence about this monument and reexamining the contemporary triumphal monuments, the article suggests another reconstruction of the monument according to the similar monuments of the same period.

\section{SALUSTIO, SILA Y LOS TROFEOS DE POMPEYO}

El autor antiguo más cercano al levantamiento de los «trofeos de Pompeyo" en los Pirineos es Salustio (86-34 a.C.). En sus Historiae, llegadas a nosotros fragmentariamente, dice: devictis Hispanis tropaea in Pyrenaei iugis costituit (sc. Pompeius) ${ }^{\prime}$. Ninguna indicación precisa, como se ve. Como resultado de la victoria sobre Sertorio, Pompeyo levanta trofeos (tropaea) -nótese bien, en

\footnotetext{
'Salustio, Hist. III, 89
}

plural-. La victoria sobre Sertorio fué el resultado de una guerra civil, en la que Pompeyo sofocó y sometió a los pueblos que apoyaron al rebelde Sertorio en el territorio de la península ibérica. Se trató de una guerra civil, que concluyó en el 71 a.C. y no de una guerra de conquista expansionista ?

Antes de pasar al análisis de otras fuentes que se refieren a este hecho, me parece importante - metodológicamente - hacerse la siguiente pregunta: ¿cómo eran los tropaea que los romanos levantaban como consecuencia de sus victorias a comienzos del s. । a.C.? ¿Tenemos alguna evidencia de este tipo de monumentos de modo que pueda servirnos de ejemplo o de modelo ilustrativo? Es evidente que el modelo arqueológico - $\mathrm{o}$ arquitectónico- ha de buscarse, no en la esfera de otras conmemoraciones, tales como monumentos funerarios, sino en lo que se ha dado en llamar el «arte triunfal» ${ }^{3}$. La respuesta es que sí, que disponemos de ejemplos contemporáneos que pueden ilustrar lo que eran y cómo eran los tropaea en la época en la que Pompeyo alzó los suyos en los Pirineos. Estos ejemplos, o estos

\footnotetext{
${ }^{2}$ Es necesario subrayar el carácter de guerra civil por lo que se dirá más adelante y porque determina el entendimiento correcto del significado de los trofeos de Pompeyo. Este aspecto no ha sido, lamentablemente, analizado en el último libro sobre Sertorio publicado en España, el de Felix García Morá, Un episodio de la Hispania Republicana: la guerra de Sertorio, Univ. de Granada, 1991, p. 358-359 que incomprensiblemente tampoco menciona las referencias de Estrabón a los trofeos (cfr. más abajo). Sobre la guerra de Sertorio en cuanto guerra civil, importantes observaciones en P. Jal , La guerre civile à Rome, PUF, 1963, passim y esp. p. 165 ss. Ver igualmente, J. van Ooteghem, Pompée le Grand, Namur, 1954, 95 ss.

${ }^{3}$ G. Ch. Picard, Les trophées romains, Paris, 1957, que estudia antecedentes, origen y evolución.
} 
testimonios, son de dos tipos: iconográficos y arqueológicos 4 .

Una cuestion previa: Iropueum o trophaeum es. originariamente, el signo de la victoria. el tronco del árbol al que se fijan las armas, los escudos y demás parafernalia, tomados al enemigos. Con el paso del tiempo, el árbol o tronco real, con armas reales, pasó a ser de piedra o de mármol y las armas se redujeron también a lo esquemático. Consecuentemente, dos trofeos. tropaia, en el vocabulario de Salustio, son dos monumentos de estas características, de piedra o de mármol, que se erigen sobre un pedestal. No se requiere otra monumentalización en principio en el periodo de comienzos del «arte triunfal", que es al que nos estamos refiriendo, $y$ al que se refieren también los trofeos de Pompeyo ${ }^{\circ}$. Porque, en efecto, el año 71 a.C. - Veleyo Paterculo recuerda que el triunfo ex Hispania de Pompeyo fué en esa precisa fecha ${ }^{7}$ - estamos todavia en un periodo en el que el «arte triunfal» romano estaba en una fase aún no suficientemente desarrollada, en la que, los maniquies con armas - ya en piedra o en mármol - eran el modelo corriente. Tenemos confirmación de ello: en primer lugar asi lo testimonian abundantemente las monedas, en cuya iconografía los encontramos asociados a los triumphatores o viri triumphales $^{\mathrm{x}} ; \mathrm{y}$, del mismo modo, lo evidencian los restos arqueológicos. Poseemos, además, una gran fortuna a este propósito, debida a un reciente descubrimiento.

El año 86 a.C. - es decir, a muy pocos años, quince, de distancia de la erección de los trofeos de Pompeyo a los que alude Salustio- el general romano Sila, tras haber reducido con éxito Atenas y el

\footnotetext{
"Floro señala en su Epitome $(1,37,6)$ que en el 122 a.C. como resultado de sus victorias sobre los allobroges, D. Ahenobarbus y Fabio Maximo erigieron torres coronadas con los trofeos de armas de los enemigos, en el escenario de las batallas (ipsis quibus dimicaverant locis saxeas erexere turres et desuper exornata armis hostilibus tropaea fixerunt). Pero el propio Floro subraya lo inusual de tal hecho (i.e. levantar torres con el maniqui encima): cum hic mos inusitutus fuerit nostris. Sobre el tema cfr. el comentario de Picard, (n. 3), p. 104 ss. y 152 ss.

'Signum victoriae; sobre el tema ver Picard, Les trophées, citado (n. 3); H. S. Versnel, Triumphus, Leiden, 1970, p. 304 ss.: esclarecedor, Isidoro, Orig. 18.2, 1-8, con Servius Gramm. ad Aen. 10.775.790. Sobre el significado e importancia del triunfo en época republicana ver en fin, W.V. Harris, Guerra e imperialismo en la Roma republicana (327-70) a.C.) Madrid, Siglo XXI, 1989.

"cfr. Picard, Les Iropheses, citado (n. 3).

7 Velleius Pat, 2.30.2.

${ }^{x}$ Cfr. M. Crawford, Reman Repuhlican Coinage, Cambridge UP 1974, (reimp. 1991) p. $373: 450$ etc. ver también, Harris, Guerra, (cit. n. 5) p. 259 ss. y multitud de ejemplos en DarembergSaglio, s.v. trophaeum.
}

Pireo, se dirigió hacia el norte, a Beocia, para enfrentarse con Arquelao, general a su vez de las tropas de Mitridates en Grecia. Se libró una batalla muy cerca de la ciudad de Queronea, en el amplio valle del rio Cefiso.

Plutareo, natural él mismo de Queronea, describe en el siglo ॥ d.C.. la campaña de Sila con detalle. Entre otras cosas dice: «inscritos sobre sus trofeos (nótese el plural) están los nombres de Ares, Nike. Afrodita... Hoy (Plutarco escribe en el siglo II d.C.. como he señalado) el trofeo de la batalla se alza en la llanura donde las fuerzas de Arquelao se extendian; pero hay otro (sc.trofeo; de aqui el plural) en lo alto de la colina de Tourion para conmemorar el circulo en el que se encerró a los bárbaros" ". Pausanias, también en el iglo. II d.C., recuerda igualmente la batalla y los trofeos que la conmemoran: "Los de Queronea tienen dos trofeos en su territorio que los romanos y Sila levantaron cuando conquistaron Taxilo y vencieron al ejército de Mitridates») ${ }^{10}$.

Un grupo de arqueólogos norteamericanos - dirigidos por John Camp de la American School of Classical Studies in Athens - ha descubierto ahora y publicado el trofeo de la colina de Tourion que conmemoraba la Victoria de Sila en Queronea ". ¿Cómo era? ¿En qué consistía el monumento? Brevemente, puesto que la detallada descripción se encuentra en el artículo citado de J. Camp, se trata de una base rectangular con una inscripción (altura 0,32 $\mathrm{cm}$; anchura $85 \mathrm{~cm}$ ) destinada a sostener el tronco de árbol en mármol o piedra local. En la inscripción se recuerda a los héroes de la batalla (Homoloijos y Anaxidamos). El tronco, con su panoplia, se ha identificado - si no es el mismo, seria uno semejantecon uno conservado en la localidad vecina de Skripiou - en el monasterio que alli existe - en Orcomenos ${ }^{12}$. El mismo Sila, en tetradracmas suyos, representa después los dos trofeos de Queronea, asi como también en denarios de Roma, del 80/81, con la cabeza de Venus, divinidad a la que se atribuye la Victoria ${ }^{13}$. Finalmente, en las cercanias de Tourion se elevó un templo a Apolo, cuyos restos han sido identificados también por los arqueólogos norteamericanos ${ }^{14}$.

Como consecuencia de lo dicho hasta aqui po-

\footnotetext{
Plut. Sull. 19.9-10

${ }_{10}^{10}$ Paus. 9.40.7.

"J. Camp (et ulii). A Trophy from the Battle of Chaironeia of 86 B.C. . A.J.4, 96, 1992, p. 443-445

12 Camp, (n. 11), p. 445, fig. 2; p. 448, fig. 6.

${ }^{13} \mathrm{cfr}$. Crawford, RRC.p. 373; Camp. (n. 11), p. 450, fig. 8 y 451, fig. 9.

it Camp, (n. 11), p. 445, fig. 13.
} 


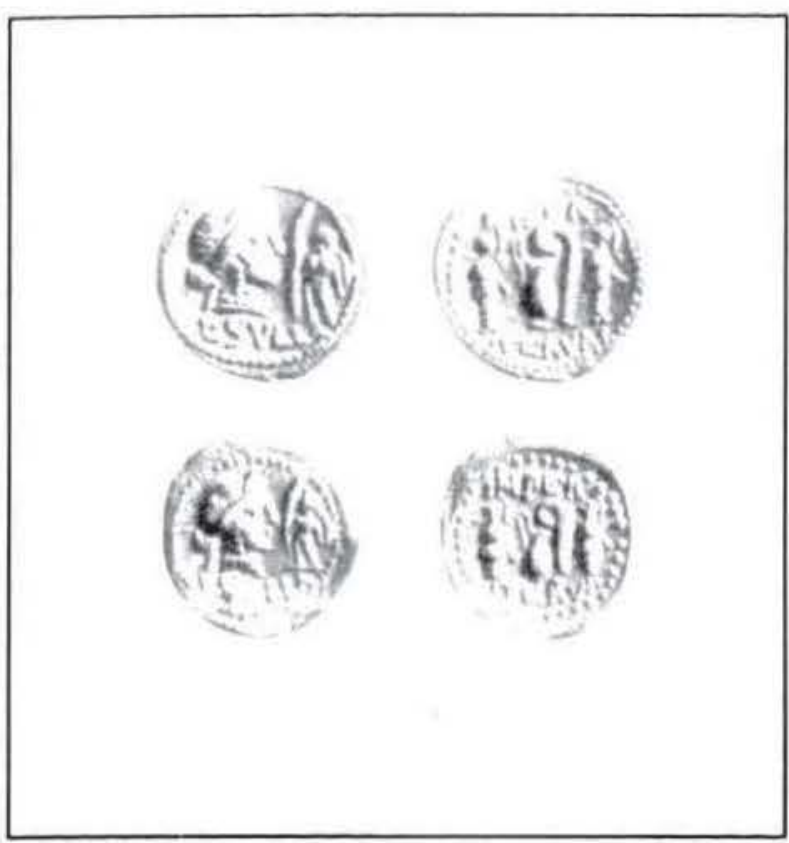

Figura 1.1. Crawford, RRC', XLVII 359/1 y 2: denario del 84-83 a.C. de Sila con los trofeos de Queronea.

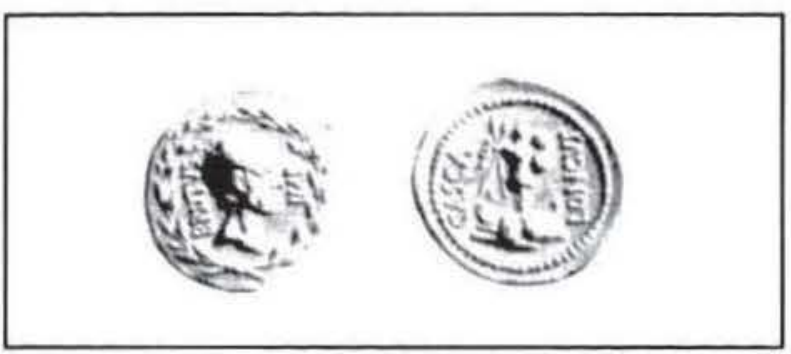

Figura 1.4. Crawford, RRC: LXI, 507, Ib: aureo de Bruto y Casca Longo, 43-42 a.C. con trofees.

demos concluir razonablemente que a 10/15 años de distancia, y moviéndonos dentro del carte triunfal romanom de la época, lo que podemos y debemos esperar de los tropaia de Pompeyo en los Pirineos, deberia de ser un monumento semejante o muy parecido al de Sila en Queronea. Colocados en una elevación, a poca distancia el uno del otro, o quizás dos maniquies sobre el mismo pedestal, que incluirian una incripción con las referencias especificas a la Victoria.

Ahora bien, ¿disponemos de alguna información más sobre los trofeos de Pompeyo que permita profundizar en sus caracteristicas? Analizaré a continuación la documentación por orden cronológico. intentando al mismo tiempo ofrecer una valoración contextual a la misma.

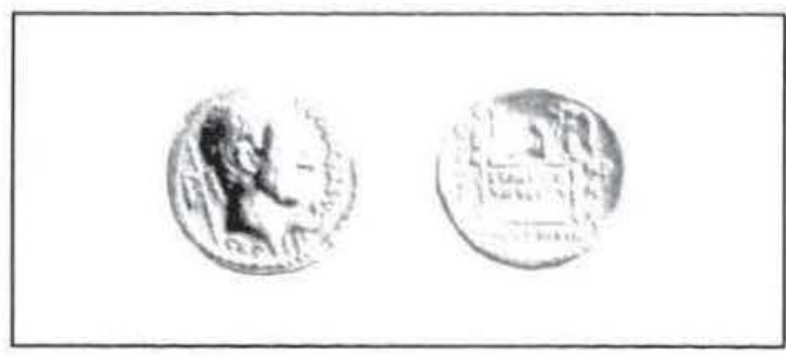

Figura 1.2 Craw ford. RRC: III 437. 2a: denario de C. Coctius Caldus 51 a. C. con trofeos recordando la victoria sobre los Sallmia

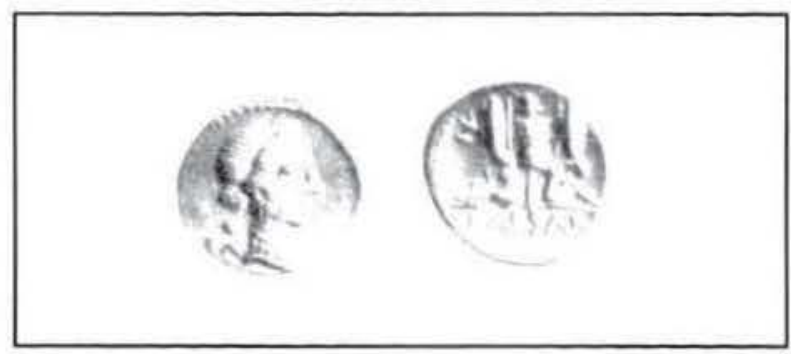

Figura 1.3.- Crawford, RRC , LV, 468, 2: denario de I. Cacsar, 46-45 a.C. con trofeos recordando triunfos en llispania.

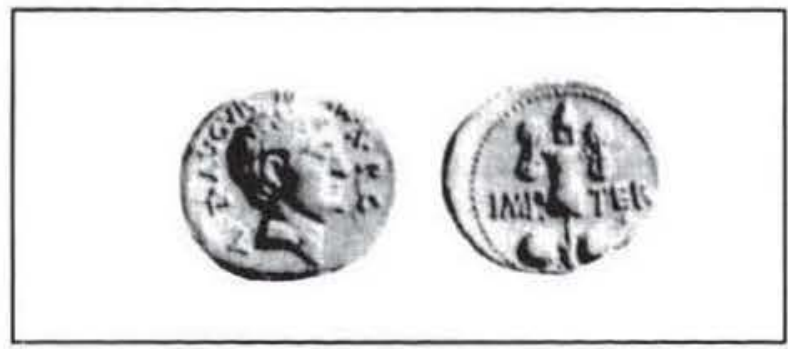

Figura 1.5. Crawford, RRC: LXIV . 536/4: denario de Marco Antonio. 37 a.C. con trofeo.

\section{LOS TROFEOS DE POMPEYO VISTOS POR LOS GEÓGRAFOS}

Estrabón no estuvo en Hispania. Pero, escribiendo en el 20 d.C., recuerda tomándolo de su fuente geográfico-descriptiva los «trofeos de Pompeyo», en varias ocasiones ${ }^{15}$. En III, 4, I, describiendo la costa meridional de la Peninsula, hace referencia al

"La fuente de Estrabón para estas referencias a los trofeos de Pompeyo debe ser una comprendida entre el 71 y el momento que escribe (ca. el año $20 \mathrm{~d}$. C.). Is probable que sea Artemidoro. La evidencia estraboniana sobre los trofeos de Pompeyo no ha sido utilizada por cjemplo por I. Roda en el íltimo articulo sobre el tema (al que volvere mas adelante): efr. I. Rodà. Els models arquitectonics dels trofeus de Pompeu als Pirineus. Homatge al Prot. Miquel Tarrablell, Barcelona, 1993, p. 645 ss. 
hecho de que desde el territorio de los edetanos uhasta los Pirineos y los trofeos de Pompeyo la costa mide 160 estadios”. Poco más adelante los recuerda otra vez III.4.7: «Entre el lugar en el que el Ebro desemboea en el mar y las alturas de los Pirineos, en las que están situados los trofeos de Pompeyo, la primera ciudad es Tarracon. Hablando de los ampuritanos y su territorio incluye una tercera mención de Estrabón sobre los trofeos de Pompeyo: «Pero algunos de los ampuritanos ocupan incluso parte de las alturas de los Pirineos hasta los trofeos que fueron erigidos por Pompeyo, pasados los cuales, corre el camino que viene de Italia ... (esta via) se dirige hacia Tarraco desde los trofeos que levantó Pompeyo..." ${ }^{16}$. En fin las menciones del geográfo se completan en el pasaje IV,1,3 en el que comenta los limites de la Narbonense y señala que el río Var constituye el limite entre esta provincia e Italia: «Desde el río Var - dice Estrabón- la costa se extiende hasta el templo de la Afrodita Pirenaica. Y es este templo, precisamente, el que marca la frontera entre la provincia de la Narbonense y el país de Iberia, aunque algunos consideran que el lugar donde están los trofeos de Pompeyo es el que marca la frontera entre Iberia y Céltica».

Varias conclusiones se pueden extraer de estos textos estrabonianos. En primer lugar, Estrabón utiliza siempre el plural para referirse a los trofeos de Pompeyo: en las menciones del libro III sobre Iberia, utiliza el genérico «anathemata Pompeiou» «las ofrendas de Pompeyo» y en el libro IV - que trata de la Galia - utiliza el más especifico tropaia, también en general, un concepto que está englobado en el anterior, esto es: trofeo es una ofrenda en cierto sentido, ofrenda representada por el maniquí con las armas ${ }^{17}$. Una segunda observación: en época de Estrabón ya los trofeos del gran Pompeyo son un elemento o hito fundamental que sirve para delimitar la frontera (horos) entre Galia e Hispania. Asi lo entienden sus fuentes geográficas e incluso en ellas hay discrepancias sobre el problema (cfr. el texto IV $, 1,3$ ). Resulta claro que las referencias de Estrabón demuestran que los trofeos están en relación o cercanía de una vía, la que desde Iberia, bordeando la costa, se dirige hacia la Galia Narbonense y luego a Italia. En un principio, en origen, los trofeos de

\footnotetext{
16 III, 4.9.

${ }^{17} \mathrm{La}$ diferencia en el uso del vocablo utilizado podría significar un cambio de fuente por parte de Estrabón.

${ }^{1 *}$ Como resultado de la politica augustea de reorganización del territorio el año 14 a.C. como consecuencia de su viaje a Hispania y Galia.
}

Pompeyo, fueron una ofrenda a la victoria dejada por el vencedor, visible para todos cuantos visitasen el territorio. Con el paso del tiempo, de poco tiempo - entre el 70 y la fuente de Estrabón- se convirtieron en un termimus territorial ${ }^{1 x}$. En este caso los trofeos están funcionando en el sentido más primigenio de su significado, en el sentido de marcar un confin al territorio del enemigo ${ }^{19}$. Casi contemporáneamente otros monumentos similares, como los arcos, pasarian a cumplir en ocasiones igualmente esta función. Este es el caso, bien atestiguado, del arcus in monte Amano que decretó construir el Senado en honor de Germánico, que recuerdan, tanto Tácito como la Tabula Siarensis ${ }^{20}$. Lo que si es claro es que para Estrabón (o mejor para sus fuentes geográficas) los trofeos de Pompeyo servian de terminus territorial, estaban cerca de la costa y además eran terminus del territorio de los ampuritanos. Trofeos de Pompeyo y Templo de Afrodita Pirenaica, no obstante, se podian confundir en cuanto a su función de límites. Ambos debian, pues, de estar cercanos y, por qué no, relacionados. No deja de ser una coincidencia que también en Queronea, junto a los trofeos de Sila, existiese un templo ${ }^{21}$.

\section{LA CURIOSIDAD DE PLINIO}

El naturalista Plinio completa el dossier más significativo que poseemos sobre los «trofeos de Pompeyo». En el libro III de su Naturalis Historia, Plinio, se ocupa de la peninsula ibérica desde el punto de vista de su organización territorial, del número de municipios, civitates, oppida y límites ${ }^{22}$ y señala -escribiendo ca. el 77 d.C.-: «El espacio antiguo de la España Citerior ha cambiado considerablemente, como el de muchos otras provincias: piénsese que Pompeyo el Grande, en los trofeos que alzaba en los Pirineos, atestiguaba haber sometido 866 oppida desde los Alpes a los confines de la España ulterior.... ahora sin embargo.... ${ }^{23}$. En otro pasaje, $\mathrm{NH}, 7,96$, vuelve a referirse a los trofeos

\footnotetext{
${ }^{19} \mathrm{cfr}$. el pasaje de Servio ad Aen. IX. 52; Liv. 1. 24. 2 ss; Liv. I, 32, 6-14.

${ }^{20}$ Tab. Siar. Frg. I, 22, Estudios sobre la Tabula Siarensis (eds. J. González-J.Arce, Madrid, 1988), CSIC, Anejos de Archivo Español de Arqueologia, IX) p. 308; Tacito, Ann. III, 83,2 y J. Arce, Tabula Siarensis: Primeros comentarios, AEspA, 37. 1984 , p. 149 ss. Sobre el significado general cfr. A. van Gennep, I riti di Passaggio, Boringheri, 1981, p. 14 ss.

${ }^{21}$ Camp. (n. 11), p. 454.

${ }^{22}$ Este es el tema del libro III de Plinio.

${ }^{23}$ Plin. $\mathrm{NH}, 3.18$.
} 
y dice: "...tras haber sometido toda el Africa, de la que se trajo como botin el nombre de Magno, volvió....a su patria en carro triunfal y rápidamente marchó al Occidente donde, alzando trofeos en los Pirineos, (excitatis in Pyrenaeo tropaeis), se añadió al mérito de su victoria el haber sometido 876 oppida desde los Alpes hasta los limites de la Hispania Ulterior; y con gran generosidad, no hizo mención de Sertorio». Finalmente en el libro 37, Plinio vuelve sobre los trofeos de Pompeyo. El naturalista está tratando en este libro de las gemas y las piedras preciosas. Y en 37,5 se refiere al personaje que en Roma fué el primero en tener una colección de gemas, Scauro; hasta Pompeyo no hubo en Roma otra colección que la suya. Pero fue éste último quien dedicó en el Capitolio la colección del rey Mitridates. Pompeyo es para Plinio el responsable de la moda de las gemas $(37,6)$ y para demostrarlo pasa a reproducir textualmente (verba ex ipsis Pompei triumphorum actis subiciam) lo que escribió éste último en las Actas de su triunfo ${ }^{24}$. Entre los muchos tesoros que se incluian erat et imago $\mathrm{Cn}$. Pompei e margaritis, un retrato de Pompeyo hecho con perlas. Este hecho suscita en el anticuario Plinio un comentario de desaprobación: aquella efigie - dice-, aquél rostro honesto, digno de veneración por todos los pueblos, estaba hecho con perlas: aquello sí que era el triunfo de la luxuria y el fin de la austeridad ${ }^{25}$. Continúa quejándose de la desmesura de tal acto para terminar: «i pero no era mucho más parecida aquella imagen tuya (non ergo illa tua similior est imago) que has puesto sobre lo más alto de los Pirineos?» 26 .

Comprendemos pues que la curiosidad de Plinio le lleva a tratar o a referirse a los trofeos de Pompeyo de muy diversa forma y en contextos bien diferentes. En el libro III, de carácter geográfico-administrativo, su preocupación era el saber el número de pueblos, municipios, colonias y las divisiones territoriales. Ello le llevó a consultar documentos: entre ellos, la inscripción que ornaba los trofeos de Pompeyo que enumeraba los 866 oppida sometidos ${ }^{27}$. Con ello Plinio produce un dato más - significati-

\footnotetext{
24 Sobre la costumbre de los triumphatores de escribir sus hazañas en tabulae cfr. Liv. XLI 28. 8-9 y otras referencias en Harris, (n. 5), p. 259-60.

is illa severitate victa et veriore luxuriae triumpho!

${ }^{26}$ El contexto permite pensar que imago aquí no es una estatua, sino un retrato.

${ }^{27}$ Entre Plin. VII, 96 y Plin. III, 18 existe una variante en el número 866 frente al 876 . El hecho no me parece especialmente relevante. Resulta inapropiado traer a colación, como hace I. Rodá, la inscripción copiada en el manuscrito BNMadrid 5.577, folio 2. ya que ésta es una imaginaria creación contraria incluso al texto pliniano: linea 9: Sertorium domuit bello servili; Plin. 96:
}

vo-sobre los monumentos que tratamos aqui: la existencia en ellos de una larga inscripción que enumeraba los oppida sometidos ${ }^{2 x}$. En el libro VII - que trata de las grandes hazañas de algunos personajes históricos - vuelve sobre el tema dando o añadiendo, en esta ocasión, más datos preciosos que permiten completar el texto de la inscripción. De hecho. la referencia del libro VII nos informa de una omisión fundamental en la inscripción, omisión que explica el uso y razones de la erección de los trofeos: Pompeyo no mencionó en su inscripción triunfal el nombre de su verdadero rival causante del «trofeo»: Sertorio. Sobre esto volveré más adelante. Baste decir ahora que los nombres de los oppida eran los de los pueblos aliados con Sertorio en la guerra civil que mantuvo contra Pompeyo. En fin, el párrafo del libro 37 de Plinio corresponde a otro de sus múltiples intereses, las obras de arte, las curiosidades anticuarias. Indirectamente, eso sí, completa aún más nuestra información sobre los trofeos pirenaicos, ya que se refiere a un retrato del propio Pompeyo que adornaba uno de los dos (o quizás los dos) monumentos. Quiero subrayar un hecho: Plinio habla primero de una imago hecha con perlas en una ocasión; y luego utiliza otra vez el vocablo imago para referirse a la representación que ornaba los trofeos: ¿estamos en este caso ante un retrato sólo o ante una estatua? (statuam hubiera sido más apropiado). Me inclino por lo primero, esto es, en los trofeos habia no una estatua, sino una imago de Pompeyo. Además, esta imago (o incluso, si se quiere, esta estatua) era visible, cercana, accesible al espectador, que podia fácilmente distinguir los rasgos definitorios del rostro de Pompeyo ${ }^{24}$. Importante aspecto a tener en cuenta en una posible reconstrucción del monumento.

el maiore animo Sertorium tacuit; cfr. I. Rodá, cit (n. 15), p. 649 que no parece haberse percatado del texto pliniano; en el trabajo de Rodá hay que corregir además amiore por maiore y Sertotirum por Sertorium.

${ }^{2 x}$ La inscripción, cuyo contenido reproduce Plinio, proviene directamente de la consulta de las acta triumphalia o del propio texto de Pompeyo en su tabula (véase supra n. 23). Puede incluso tratarse de una visión directa de Plinio durante su estancia y viajes en Hispania: sobre el tema y fuentes de Plinio sobre la Península cfr. R. Syme, Pliny the Procurator, Roman Papers II, Oxford 1979 , p. $742-773$ (esp. p. 755 y ss.).

${ }^{29}$ Trofeos con esculturas coronando la columna colocada entre los dos maniquies cfr. Camp, (n. 11), p. 448-449. La estructura de los de Pompeyo parece sustituir la estatua por el retrato. Los trofeos que aparecen en las monedas reproducen esquemáticamente el monumento triunfal real. El maniquí con las armas, o mejor. los maniquies -constituyen el elemento esencial o imprescindible, que luego se adornan con un aderezo arquitectónico-. La evolución de este tipo dará como resultado la grandiosidad de monumento de La Turbie: cfr. J. Formigé, Le trophée des Alpes (La Turbie), Gallia Suppl.», 1949; RE, VII A 661 y RE, Suppl. XI, 1269. 
Hagamos ahora una sintesis de lo dicho y de la informacion que ofrecen los textos que hemos analizado sobre los trofeos de Pompeyo, para luego analizar otros aspectos que contribuyen a la comprensión más rigurosa de los monumentos.

1. Salustio. el más cercano a los hechos, da una noticia escueta de los trofeos, propia de una narración analistica. que no permite otra cosa que constatar que se alzaron trofeos en los Pirineos tras la guerra con Sertorio. Estos trofeos se alzaron para celebrar la victoria sobre el rebelde y sus aliados.

2. Cuando Estrabón describe los trofeos de Pompeyo estos han pasado a ser o se han convertido en un terminus fronterizo que se utilizaba para diferenciar el territorio de las provincias de Hispania y de las Galias. Servian además como limite del territorio ampuritano. Junto a los trofeos existia un templo - templum Veneris - que podia confundirse con el confin, o servir de confin. Algunos geógrafos asi lo consideraban ${ }^{\text {wo. }}$. Estrabón utiliza y está intere sado en los trofeos pirenaicos sólo desde este punto de vista geográfico-territorial. Consiguientemente entre el 71 a.C. y la fuente de Estrabón - antes del 14 d.C. al menos - los trofeos han cambiado de significado, o mejor, han añadido a su significado primigenio un componente más, el de terminus fronterizo. Este hecho ¿pudo implicar una monumentalización de los dos maniquies existentes ya en época de Pompeyo? Es muy probable; y es igualmente verosimil que haya sido el propio Augusto quien hiciera esa tranformación ". Por el texto de Estrabón no podemos deducir nada más.

3. Plinio, en fin, nos informa que los trofeos comprendian también una inscripción con la mención expresa de los 866 oppida sometidos, inscripción que no hacia mención del rival sobre el que se fundamentó el triunfo $-\mathrm{y}$ consecuentemente los trofeos-, es decir, de Sertorio. Además en los trofeos, y situada en un lugar sobre el que podemos especu-

\footnotetext{
${ }^{10}$ Las disensiones entre los geógrafos están recogidas en el propio Estrabón. Sobre el Templum Veneris efr. Mela 2.84 (insignis fano): Plin. NH. 3.22: Liv. XXVI, 19; Aus Ep. 9.27. Schulten. A., Iherische Landeskunde, I. Estrasburgo-Kehl, 1955, p. 178 ss. Este templo antiquisimo, debia estar en un principio relacionado con los navegantes, como tantos otros santuarios de la época de la expansión griega (de hecho, es mencionado por Avieno en su periplo). También el Trofeo de la Turbie se hallaba dividiendo Galia c Italia y en-relación con la via Augusta. El trofeo de Adamklissi se encuentra en el cruce de las vias MarcianopolisNoviodunum y Tomi-Durustorum-Nicopolis ad Istrum.

${ }^{11}$ Debo esta sugerencia a X. Dupré, que ha puesto de manifiesto la relación Trofeos de Pompeyo-Arco de Martorell-Arco de Bará como método en la reorganización territorial augustea en su libro (en prensa) El Arco de Burá.
}

lar más adelante. hubo una imago realista de Pompeyo, imago visible y fäcilmente discernible por el espectador.

Dicho esto, pasamos al motivo de la erección de los trofeos y al problema de la ausencia expresa de Sertorio en la inscripción.

\section{SERTORIO Y LOS TROFEOS DE POMPEYO}

La apropiada contextualización de los trofeos de Pompeyo, que se mencionan en las fuentes que he analizado, exige referirse a la causa y razón de su levantamiento. Conviene pues recordar que los trofeos pirenaicos son el resultado de la victoria de Pompeyo sobre Sertorio. Es bien conocido este episodio entre los historiadores de la República romana y por ello no voy a referirme aquí a él in extenso $^{32}$. Solo quiero subrayar que se trató de un bellum civile entre itálicos $\mathrm{y}$, consiguientemente, de una guerra no justa (bellum iniustum) que no daba derecho al triunfo ${ }^{3,3}$ ni a su celebración. Pompeyo, al alzar un monumento en recuerdo de su victoria sobre Sertorio y sus aliados, no tenia ninguna justificación si no era alterando el sentido de los hechos y omitiendo el nombre del rival, haciendo asi aparecer el acto como una guerra contra pueblos extranjeros. Por ello, como expresamente anota Plinio, no mencionó a Sertorio en la inscripción, aunque el naturalista atribuye la omisión a la magnanimidad del vencedor ${ }^{34}$. Atribuyéndose sólo el hecho de la conquista y sometimiento de pueblos en Hispania y Galia, Pompeyo desviaba inteligentemente el problema y hallaba asi una justificación al monumento que, desde el punto de vista propagandistico, le favorecia. No mencionó tampoco el nombre de Metelo, su colega que tanto habia contribuido al éxito de las operaciones en la Península. No pasó este hecho desapercibido a los antiguos. Floro ${ }^{35}$ señala, sin lugar a dudas, que los trofeos pirenaicos pretendian hacer aparecer a los ojos de todos que había existido un triunfo sobre pueblos exteriores, cuando en realidad se habia tratado de una lucha entre facciones politicas romanas: sic recepta in pacem Hispania. victores duces externum id magis quam civile be-

\footnotetext{
12 Entre otros cfr. J, van Ooteghem. Pompie le Grand, Lounain, 1954; hay que recordar el viejo libro de A. Schulten. Sertorio, y el de Félix Garcia Mora (citado en n. 2).

11 Entre otros, P. Jal, La guerre civile à Rome, PUF, 1963 passim.

${ }^{4}$ Asi Ootgehem, cit. (n. 32) p, 134.

is II, 10.9 .
} 
Ilum videri voluerumt ut triumpharent. Los «trofeosm eran, por tanto. una falsificacion y no hallaban justificación alguna. El historiador Dion Casio refleja igualmente cual fuc el estado de opinion ante el hecho: ('esar. de regreso hacia Roma en el 49 a.C.. después de sus victorias en Hispania, no levantó trofeos eporque entendió que Pompeyo no habia conseguido un buen nombre habiéndolo hechom ${ }^{3 t}$. Y se limitó a elevar un gran altar no lejos de los trofeos de su rival. Pero no por modestia - como pretenden algunos- ${ }^{37}$. sino como resultado de un cálculo perfectamente premeditado ${ }^{i x}$. Porque tampoco la guerra de César en Hispania, en aquella ocasión. habia sido una guerra justa, sino que, al igual que la de Pompeyo, fue una guerra civil. César pretendió evitar las criticas en Roma y se mostró estricto cumplidor de la norma ancestral que los romanos poseian sobre la erección de trofeos después de las victorias: frente a la vanidad y falsificación de Pompeyo, César aparecia como un estricto cumplidor de la religión y añadía así un motivo más que reprochar a su gran rival, Pompeyo, en el escenario politico de la capital.

\section{LA IDENTIFICACIÓN ARQUEOLÓGICA DE LOS TROFEOS DE POMPEYO}

Como es lógico los arqueólogos han tratado de identificar el lugar y los restos de los trofeos de Pompeyo en algún punto de los Pirineos. Sobre el tema se han hecho multitud de especulaciones $y$ propuestas ${ }^{31}$. Parece razonable pensar que se encuentran cerca de la costa, en lo alto de la montaña pirenaica de forma que fueran visibles y que se encuentren en la proximidad de la via que unía Tarraco con la Narbonense. Ocurre, sin embargo, que, en mi opinión, en esta búsqueda ha primado la imprecisión en el análisis de los textos y una cierta atrac-

\footnotetext{
16 Dion Cass, XLI, 24.3.

"El hecho no fué debido ua la modestian de J. César , como pretende 1. Rodá (n. 15).

* Sobre el tema, St. Weinstock, Divus hulius, Oxford, 1971. pp. 37 con la n. 8 (que en mi opinión equivocadamente, pretende unir los Trofeos de Pompeyo con Alejandro). Weinstock no hace tampoco referencia al hecho ilegal de elevar los trofeos por parte de Pompeyo. Las referencias de Amiano y de Diodoro a los altares de Alejandro en la India no tienen nada que ver con el problema que estamos tratando, pero el haber sido invocados por Weinstock ha originado una superficial mención por parte de Isabel Rodá.

${ }^{10} \mathrm{Ver}$ los tradicionales estudios de Formigé (citado en n. 29) y de Picard (citado n, 3). Ahora, recientemente, Isabel Rodá, Els models... citado, n. 15).
}

cion e influencia de momentos posteriores a los trofeos de Pompeyo que se han querido proponer como ejemplos o modelos arquitectónicos para los mismos siendo posteriores a ellos. Los arqueólogos han tratado de retrotraer a la época de Pompeyo modelos creados con posterioridad, en épocas muy alejadas, intentando ver en ellas o, mejor, sintiéndose sugestionados por monumentos como el trofeo de la Turbic de época augustea o, incluso, por el monumento de Trajano en Adamklissi ta. Y no ha faltado quien, al mismo tiempo, ha buscado modelos -imaginativamente en épocas muy anteriores en los siglos IV y $\|$ antes de Cristo ${ }^{+1}$. Este es un juego peligroso y metodológicamente incorrecto. Por una simple razon: porque no conservamos nada del monumento o monumentos de Pompeyo que permita establecer un precedente. $\mathrm{Y}$ en segundo término -y más importante - porque, como he señalado, la esfera contextual en la que se crean los trofeos de Pompeyo corresponde a la de la época: $y$ hemos comprobado que, iconográficamente y también arqueológicamente, los tropaia de ca. el 71 a.C. consistian en un pedestal, una inscripción y eventualmente una estatua y/o el retrato del vencedor colocada sobre el tronco de árbol que sostiene las armas ${ }^{42}$. Pienso que mientras no dispongamos de evidencia clara no es licito retrotraer la monumentalización y magnificencia de este tipo de monumentos en época de Augusto a la época de Pompeyo y concretamente al año 71 a.C. ${ }^{43}$.

El reciente y afortunado descubrimiento de los trofeos de Sila en Queronea permite razonablemente conocer cómo era el arte triunfal de la época. Y permite, asimismo, imaginar cómo fueron - al menos en un primer momento- los trofeos erigidos por Pompeyo en los Pirineos. El monumento originario pudo ser o consistir en un pedestal con una

\footnotetext{
III Por ejemplo. Isabel Rodá, (n. 15), p. 650.

"El ejemplo es igualmente 1. Rodá. (n. 15), que trae a colación, como modelo de los trofeos de Pompeyo, el mausoleo de Belevi del s: III a.C. en las cercanias de Efeso. Un mausoleo y los trofeos de Pompeyo no tienen nada que ver, teniendo en cuenta sobre todo la escasa documentación arqueológica que se ha identificado con los trofeos de Pompeyo en los Pirineos. El texto de Pausanias, citado por I. Rodá, sobre la tumba de Pirro en Argos (Paus. II, 21.4 (y no II, XX, I, 4 como aparece en Rodá) no tiene nada que ver con el tema cfr. M. Torelli, Pausania, guida della Grecia, vol. II (ed. Lorenzo Valla, 1986) p. 283 donde se evidencia por las excavaciones del ágora de Argos que el monumento lünebre de Pirro era circular

+2 L.a tesis de I. Rodá. I.c. resulta contradictoria e invalidada por el descubrimiento de los trofeos de Sila en Queronea.

4t Los trofeos de Pompeyo tenian sus iguales en el arte triunfal contemporáneo. La confirmación son los trofeos de Queronea.
} 
estatua entre los dos maniquies, tal y como se propone en la fig. 2, o en dos pedestales con estatua + maniquies. No hay otra "evidencia». Lo que arqueólogos franceses y españoles han descubierto en Panissars es una estructura que merece un detenido y riguroso análisis. Es posible -y lo avanzo aqui como hipotesis solamente - que se trate de una de las practenturae que constituian la defensa de los caminos - sistema creado ya por Augusto - como testimonia Suetonio, luego reforzados y reutilizados en época tardorromana th . Pero, por el momento, identificarlo con los trofeos de Pompeyo me parece, rigurosamente hablando, simplemente prematuro e indemostrable. Probablemente no son los trofeos de Pompeyo ilícitamente erigidos para recordar la victoria sobre Sertorio. ${ }^{45}$

\section{AGRADECIMIENTOS}

Agradezco muy sinceramente a Walter Trillmich, Pierre Gros y a Emilio Rodríguez Almeida el haber leido este manuscrito y haberme hecho indicaciones preciosas. La responsabilidad del texto es exclusivamente mía. A Fabienne Burkhalter que ha sido, como siempre, quien me ha dado, con sus críticas y sugerencias, una ayuda inestimable en algunos as-

\footnotetext{
44 Lo que han descubierto los arqueólogos franceses y españoles (Rodá, (n. 15), p. 644 ss.) es posible que sea una de las praetenturae o clausurae que formaban parte de la defensa pirenaica (Schulten, Iberische Landeskunde, (cit. n. 30) p. 175 ss.) y el sistema de defensa atestiguado en otras zonas montañosas y fronterizas del Imperio en época tardia, cfr. Notitia Dignitatum. Occ. XXIV (ed. Seeck) ó ND, Or. XXXVII (Seeck).

4s Picard consideraba que los Trofeos de Pompeyo debian ser una torre redonda (tour) del tipo de La Turbie o Adamklissi, pero es adelantar cronológicamente los hechos (cit. n. 3, p. 184).
}

pectos. En fin. a (ionzalo Sáenz, de la Escuela Española de Historia y Arqueologia del C.S.I.C. en Roma, por haber tenido la gentileza de ayudarme en el dibujo reconstruction.
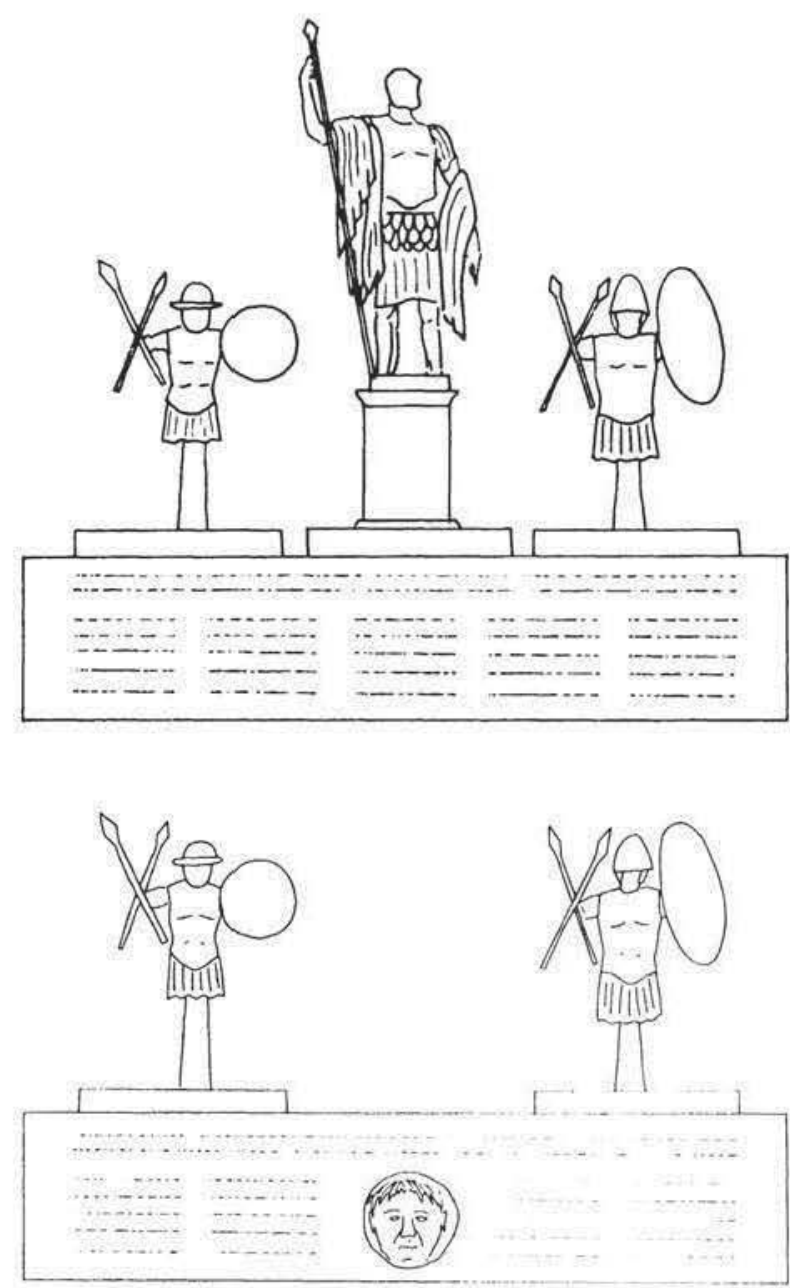

Figura 2.-Reconstrucción hipotética propuesta para los trofeos de Pompeyo en los Pirineos. 